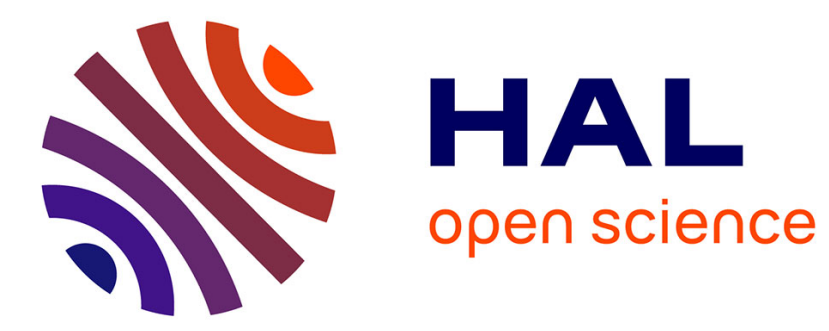

\title{
An evaluation metric for intraseasonal variability and its application to CMIP3 twentieth-century simulations
}

Prince K. Xavier, Jean-Philippe Duvel, Pascale Braconnot, F.J. Doblas-Reyes

\section{To cite this version:}

Prince K. Xavier, Jean-Philippe Duvel, Pascale Braconnot, F.J. Doblas-Reyes. An evaluation metric for intraseasonal variability and its application to CMIP3 twentieth-century simulations. Journal of Climate, 2010, 23 (13), pp.3497-3508. 10.1175/2010JCLI3260.1 . hal-01136715

\section{HAL Id: hal-01136715 https://hal.science/hal-01136715}

Submitted on 27 Mar 2015

HAL is a multi-disciplinary open access archive for the deposit and dissemination of scientific research documents, whether they are published or not. The documents may come from teaching and research institutions in France or abroad, or from public or private research centers.
L'archive ouverte pluridisciplinaire HAL, est destinée au dépôt et à la diffusion de documents scientifiques de niveau recherche, publiés ou non, émanant des établissements d'enseignement et de recherche français ou étrangers, des laboratoires publics ou privés. 


\title{
An Evaluation Metric for Intraseasonal Variability and its Application to CMIP3 Twentieth-Century Simulations
}

\author{
PRINCE K. XAVIER* AND JEAN-PhILIPPE DUVEL \\ Laboratoire de Meteorologie Dynamique, Ecole Normale Superieure, Paris, France \\ PASCALE BRACONNOT \\ Laboratoire des Sciences du Climat et de l'Environnement, Gif-sur-Yvette, France \\ FRANCISCO J. DOBLAS-REYES \\ European Centre for Medium-Range Weather Forecasts, Reading, United Kingdom
}

(Manuscript received 26 May 2009, in final form 5 February 2010)

\begin{abstract}
The intraseasonal variability (ISV) is an intermittent phenomenon with variable perturbation patterns. To assess the robustness of the simulated ISV in climate models, it is thus interesting to consider the distribution of perturbation patterns rather than only one average pattern. To inspect this distribution, the authors first introduce a distance that measures the similarity between two patterns. The reproducibility (realism) of the simulated intraseasonal patterns is then defined as the distribution of distances between each pattern and the average simulated (observed) pattern. A good reproducibility is required to analyze the physical source of the simulated disturbances. The realism distribution is required to estimate the proportion of simulated events that have a perturbation pattern similar to observed patterns. The median value of this realism distribution is introduced as an ISV metric. The reproducibility and realism distributions are used to evaluate boreal summer ISV of precipitations over the Indian Ocean for 19 phase 3 of the Coupled Model Intercomparison Project (CMIP3) models. The 19 models are classified in increasing ISV metric order. In agreement with previous studies, the four best ISV metrics are obtained for models having a convective closure totally or partly based on the moisture convergence. Models with high metric values (poorly realistic) tend to give (i) poorly reproducible intraseasonal patterns, (ii) rainfall perturbations poorly organized at large scales, (iii) small day-to-day variability with overly red temporal spectra, and (iv) less accurate summer monsoon rainfall distribution. This confirms that the ISV is an important link in the seamless system that connects weather and climate.
\end{abstract}

\section{Introduction}

The intraseasonal variability (ISV) of tropical convection is characterized by large-scale organized perturbations with maximum amplitudes over the Indo-Pacific region. In boreal winter, they propagate eastward from the western Indian Ocean to the central Pacific and are generally referred to as the Madden-Julian oscillation

\footnotetext{
* Current affiliation: Met Office Hadley Centre, Exeter, United Kingdom.

Corresponding author address: Prince K. Xavier, Met Office Hadley Centre, FitzRoy Road, Exeter EX13PB, United Kingdom. E-mail: prince.xavier@metoffice.gov.uk
}

(MJO) (Madden and Julian 1994). The character of ISV in boreal summer over the Indian Ocean (see Goswami 2005 for a review) is rather distinct. It initiates around $5^{\circ} \mathrm{S}$ in the eastern Indian Ocean and propagates northeastward with a speed of about $1^{\circ}$ latitude per day. With typical periods of 30-40 days, these propagating rainbands reach up to $25^{\circ} \mathrm{N}$ and contribute largely to the rainfall over India. The summer ISV shows marked seasonality in accordance with the large seasonal variations of the intertropical convergence zone (ITCZ) over the Indian monsoon region (Bellenger and Duvel 2007). The strong convective ISV center is over the eastern equatorial Indian Ocean in May and shifts to the Arabian Sea (along the west coast of India) and to the Bay of Bengal in June. The ISV variance patterns persist for the rest of the monsoon period (July, 
August, and September) but with a reduced amplitude. This seasonality in the ISV is intimately related to the ocean thermal structure and atmosphere-ocean feedbacks (Xavier et al. 2008; Bellenger and Duvel 2007; Duvel and Vialard 2007). The ISV is an important component of the Asian summer monsoon system that can modulate the synoptic weather systems (Goswami et al. 2003) and contribute to the seasonal rainfall and its interannual variability (e.g., Goswami et al. 2006). Therefore, the accurate representation of the ISV in climate models is important for monsoon forecasting at a range of time scales.

The representation of the ISV in general circulation models (GCMs) has always been a challenge, primarily due to its strong dependence on the physical parameterizations (Lin et al. 2008, 2006; Waliser et al. 2003; Sperber et al. 2001; Slingo et al. 1996). In a recent study Xavier et al. (2008) assess the representation of summer ISV over the Indian Ocean in the European climate models participating in the Development of a European Multimodel Ensemble System for Seasonal-to-Interannual Prediction (DEMETER) project. Importantly, the lack of large-scale organization of convection was regarded as a major cause of the poor representation of ISV in the DEMETER models. Lin et al. (2008) analyzed the summer ISV represented in 14 Intergovernmental Panel on Climate Change (IPCC) Fourth Assessment Report (AR4) models (section 2) and found that the models show a wide range of skill in the representation of summer ISV, often with reduced amplitudes and overreddened spectra.

Most of these studies have employed methodologies based either on empirical orthogonal functions (EOFs), lead-lag correlations, composites or wavenumberfrequency spectral analysis (Wheeler and Weickmann 2001). Xavier et al. (2008) have shown that, while the use of an average EOF (or composites) for a season may be robust in the observations, caution should be taken on such a priori assumptions on the robustness of the simulated ISV. As suggested in Goulet and Duvel (2000, hereafter GD2000), for an intermittent phenomenon with large differences between events, the use of a few EOFs or a single composite might result in quantities that are pure mathematical without much physical significance. Lin et al. (2008) present an evaluation of the relative amplitudes of northward wavenumbers (extracted using wavenumber-frequency spectra between $45^{\circ} \mathrm{S}$ and $45^{\circ} \mathrm{N}$ with constraints on the meridional periodicity). The leadlag correlations that they have used to compare the northward propagation of rainfall anomalies in the models pertain to the issue of whether the intraseasonal events are reproducible in the models. The Climate Variability and Predictability (CLIVAR) MJO working group has developed a set of diagnostics that are based on reprojection of actual outgoing longwave radiation (OLR) and wind signals on a couple of observed EOFs (Wheeler and Hendon 2004). Using this index on a GCM simulation output will extract the time evolution of the so-defined MJO signal, but with no precise information on the GCM representation of the intraseasonal perturbation patterns. Moreover, these diagnostics are specifically designed for zonally propagating intraseasonal perturbations confined between $15^{\circ} \mathrm{S}$ and $15^{\circ} \mathrm{N}$. Therefore, the poleward propagating monsoon ISV during boreal summer is not accurately diagnosed with the Wheeler and Hendon index. An eventwise approach for the assessment of the tropical ISV in the climate models was first introduced by Xavier et al. (2008). This method is based on local mode analysis (LMA) originally developed by GD2000. It provides the amplitude, phase, degree of large-scale organization, and period of each organized convective ISV event. The associated characteristics in other fields such as the sea surface temperature and winds can also be derived from this analysis technique.

The objective of this study is to evaluate two major aspects of the intermittent ISV, namely, (i) the reproducibility of the pattern of intraseasonal events and (ii) their degree of realism. Based on these diagnostics an evaluation metric is defined that can objectively evaluate the ISV in different models and potentially assess the role of different model physics in the representation of the ISV. A brief description of the climate models and observations is given in section 2. The LMA results of summer ISV in phase 3 of the Coupled Model Intercomparison Project (CMIP3) are described in section 3. Based on the LMA, measures of the reproducibility and degree of realism of the large-scale organized perturbation patterns of ISV are defined in section 4 and a model evaluation metric is presented. This metric is applied to evaluate the relationship between high frequency variability and the seasonal mean rainfall climate in the models (section 5) and results are summarized in section 6 .

\section{Models and data}

Major international modeling centers have performed long-term simulations of the twentieth-century climate in order to better assess their representation of the presentday climate in preparation for the twenty-first-century climate sensitivity experiments for the IPCC fourth Assessment Report. Most of the modeling centers used the latest versions of their models, which incorporate stateof-the-art research results. These include, for example, implementation of prognostic cloud microphysics schemes, different triggering and closure solutions, and the consideration of some processes such as convective momentum transport in deep convection schemes. Moreover, many modeling centers increased their model horizontal and 
vertical resolutions and some conducted experiments with different resolutions. Therefore, it is of interest to assess the ISV simulations in these new generation climate models to look at the effects of the updated physical processes, higher resolution, and air-sea coupling. Such an evaluation is also important for evaluating the general performance of the climate models used for climate change projections in the IPCC AR4. The model outputs are archived in the CMIP3 multimodel database at the Program for Climate Model Diagnosis and Intercomparison (PCMDI). The details of the horizontal resolution, closure, and trigger of different convective schemes in 19 climate IPCC AR4 models are summarized from the IPCC AR4 (http://www.ipcc-data.org/ar4/gcm_data.html) and are listed in Table 1 . Daily rainfall data from the models are used for the computation of ISV. Observed rainfall ISV is derived from the $1^{\circ}$-daily (1DD) data of the Global Precipitation Climatology Project (GPCP) (Huffman et al. 2001). The rainfall in most models covers a period of 40 years, while the 1DD GPCP data is for the period 1997-2006.

\section{Local mode analysis of summer ISV}

The intraseasonal variability of deep convection over the Indo-Pacific region is an intermittent phenomenon presenting various perturbation patterns depending mostly, but not uniquely, on season. Owing to the relatively long periodicity of the perturbation (around 40 days) in regard to the seasonal evolution of the ITCZ, two perturbations succeeding one another in time are rarely similar (GD2000). However, as shown in Duvel and Vialard (2007) and in the following, the observed perturbation pattern for a given season is quite reproducible from one event to another if one considers only a given basin (i.e., the Indian Ocean basin) instead of the whole Indo-Pacific region. In this case, the seasonal average perturbation pattern well represents the ensemble of intraseasonal events. This good reproducibility shows that robust physical processes are at the origin of the intraseasonal variability of the convection at a basin scale. Reproducibility is thus an interesting characteristic of the intraseasonal variability and has to be correctly simulated by coupled GCMs.

The metric presented here quantifies the reproducibility and the realism of the intraseasonal variability simulated by a given GCM. The reproducibility index is a measure of the similarity between each element of an ensemble of patterns and the average pattern for this ensemble (this also applies to observations). The realism is a measure of the similitude between each element of the ensemble of patterns simulated by a GCM and the observed average pattern. For both observed and simulated time series, the ensemble of patterns is extracted using the LMA technique. This technique is fully explained and validated in GD2000 and in Duvel and Vialard (2007). Here we only give a brief account of the main features of this technique. The LMA is applied to a time series $\mathbf{s}_{x}(t)$, where $x$ is a region and $t$ is the time step (1 day, $1 \leq t \leq T$ ). The LMA aims to detect different organized perturbations that succeed one another in time. Here, the input signal $s_{x}(t)$ is the precipitation time series bandpass filtered between 20 and 90 days. Since most of the intraseasonal variance is between 30 and 80 days (e.g., Wheeler and Hendon 2004), we consider that the 20-90-day band is sufficiently large to encompass all of the variability that can possibly be identified as a realistic intraseasonal variability in the GCMs.

The LMA is based on a series of complex EOF (CEOF) computation done on a running time section. The length of this time section is small in regard to the time scale considered so that the percentage of variance explained by the first CEOF is large. The pattern of this first CEOF thus well represents the actual intraseasonal variability for the corresponding time section. Here, we use a time section of 90 days and the running analysis is performed with a time step $m$ of 5 days. For each time step $m$, the first CEOF characterizes the intraseasonal perturbation in the corresponding 90-day time section. These characteristics are (i) a temporal spectrum $\boldsymbol{\psi}_{m}(k)$, (ii) a spatial pattern $\mathbf{Z}_{m}(x)$, and (iii) a percentage of variance $\Pi_{m}$.

Here, the cross-spectrum matrix of the CEOF analysis is computed only for the five first harmonics (i.e., 18 to 90 days), the signal for the remaining 40 harmonics being negligible, so that $1 \leq k \leq 5$. The first eigenvector of this matrix is the temporal complex spectrum $\boldsymbol{\psi}_{m}(k)$ that is used to compute the corresponding spatial pattern $\mathbf{Z}_{m}(x)$. Here $\mathbf{Z}_{m}(x)$ is complex and gives the regional amplitude and relative phase of the event associated with the spectrum $\boldsymbol{\psi}_{m}(k)$. The aim is now to extract an ensemble of intraseasonal events from all CEOF analyses performed with the time steps $m$. As shown in GD2000, maxima in the $\Pi_{m}$ time series correspond to 90-day time sections centered on an intraseasonal perturbation well organized at large scale. The patterns for adjacent time sections are similar. By contrast, minima in the $\Pi_{m}$ time series correspond to time sections centered on transition between two different intraseasonal events. The ensemble of maxima in the $\Pi_{m}$ time series thus corresponds to an ensemble of intraseasonal events associated with an ensemble of patterns.

Following the method detailed in GD2000, it is possible to compute an average spatial perturbation pattern $\mathbf{Z}(x)$ from an ensemble of intraseasonal events. If $\mathbf{Z}(x)$ is computed from all intraseasonal events obtained from 
TABLE 1. IPCC AR4 models and their AGCM features.

\begin{tabular}{|c|c|c|c|}
\hline Model label & Institution & $\begin{array}{l}\text { Equivalent grid } \\
\text { resolution }\end{array}$ & Deep convection \\
\hline bccr_b2_0 & $\begin{array}{l}\text { Bjerknes Centre for Climate } \\
\text { Research, Norway }\end{array}$ & $2.8^{\circ} \times 2.8^{\circ}(\mathrm{T} 42)$ & Bougeault (1985) \\
\hline mpi_echm5 & $\begin{array}{l}\text { Max Planck Institute for } \\
\text { Meteorology, Germany }\end{array}$ & $2.8^{\circ} \times 2.8^{\circ}(\mathrm{T} 42)$ & $\begin{array}{l}\text { Tiedtke (1989); } \\
\quad \text { Nordeng (1994) }\end{array}$ \\
\hline echo_miug & $\begin{array}{l}\text { Meteorological Institute of the } \\
\text { University of Bonn, Germany }\end{array}$ & $3.75^{\circ} \times 2.8^{\circ}(\mathrm{T} 30)$ & Tiedtke (1989) \\
\hline cnrm_cm_3 & $\begin{array}{l}\text { Centre National de Recherches } \\
\text { Météorologiques, France }\end{array}$ & $2.8^{\circ} \times 2.8^{\circ}(\mathrm{T} 42)$ & Bougeault (1985) \\
\hline gfdl_c2_0 & $\begin{array}{l}\text { National Oceanic and Atmospheric } \\
\text { Administration (NOAA)/Geophysical } \\
\text { Fluid Dynamics Laboratory (GFDL), } \\
\text { United States }\end{array}$ & $2.5^{\circ} \times 2.0^{\circ}$ & $\begin{array}{l}\text { Moorthi and } \\
\text { Suarez (1992) }\end{array}$ \\
\hline csiro_3_0 & $\begin{array}{l}\text { Commonwealth Scientific and } \\
\text { Industrial Research } \\
\text { Organisation (CSIRO), } \\
\text { Australia }\end{array}$ & $1.875^{\circ} \times 1.875^{\circ}(\mathrm{T} 63)$ & $\begin{array}{l}\text { Gregory and } \\
\quad \text { Rowntree (1990) }\end{array}$ \\
\hline ukmo_hcm3 & Met Office, United Kingdom & $1.25^{\circ} \times 1.875^{\circ}$ & $\begin{array}{l}\text { Gregory and } \\
\quad \text { Rowntree (1990) }\end{array}$ \\
\hline mri_2_3_2 & $\begin{array}{l}\text { Meteorological Research } \\
\text { Institute, Japan }\end{array}$ & $2.8^{\circ} \times 2.8^{\circ}(\mathrm{T} 42)$ & $\begin{array}{l}\text { Pan and } \\
\quad \text { Randall (1998) }\end{array}$ \\
\hline miro_mres & $\begin{array}{l}\text { Center for Climate System } \\
\text { Research, Japan }\end{array}$ & $2.8^{\circ} \times 2.8^{\circ}(\mathrm{T} 42)$ & $\begin{array}{l}\text { Pan and } \\
\quad \text { Randall (1998) }\end{array}$ \\
\hline csiro_3_5 & CSIRO, Australia & $1.875^{\circ} \times 1.875^{\circ}(\mathrm{T} 63)$ & $\begin{array}{l}\text { Gregory and } \\
\quad \text { Rowntree (1990) }\end{array}$ \\
\hline ingv_ech4 & $\begin{array}{l}\text { Istituto Nazionale di Geofisica e } \\
\text { Vulcanologia, Italy }\end{array}$ & $3.75^{\circ} \times 2.8^{\circ}(\mathrm{T} 30)$ & Tiedtke (1989) \\
\hline ncar_csm3 & $\begin{array}{l}\text { National Center for Atmospheric } \\
\text { Research (NCAR), United States }\end{array}$ & $1.4^{\circ} \times 1.4^{\circ}(\mathrm{T} 85)$ & $\begin{array}{l}\text { Zhang and } \\
\text { McFarlane (1995) }\end{array}$ \\
\hline ncar_pcm1 & NCAR, United States & $2.8^{\circ} \times 2.8^{\circ}(\mathrm{T} 42)$ & $\begin{array}{l}\text { Zhang and } \\
\text { McFarlane (1995) }\end{array}$ \\
\hline cgcm3_T47 & $\begin{array}{l}\text { Canadian Centre for Climate } \\
\text { Modeling and Analysis, Canada }\end{array}$ & $2.5^{\circ} \times 2.5^{\circ}(\mathrm{T} 47)$ & $\begin{array}{l}\text { Zhang and } \\
\text { McFarlane (1995) }\end{array}$ \\
\hline cgcm3_T63 & $\begin{array}{l}\text { Canadian Centre for Climate } \\
\text { Modeling and Analysis, Canada }\end{array}$ & $1.875^{\circ} \times 1.875^{\circ}(\mathrm{T} 63)$ & $\begin{array}{l}\text { Zhang and } \\
\text { McFarlane (1995) }\end{array}$ \\
\hline ipsl_cm_4 & Institut Pierre-Simon Laplace, France & $3.75^{\circ} \times 2.5^{\circ}$ & Emanuel (1991) \\
\hline inm_cm3_0 & $\begin{array}{l}\text { Institute of Numerical } \\
\text { Mathematics, Russia }\end{array}$ & $5^{\circ} \times 4^{\circ}$ & Betts (1986) \\
\hline fgoals1_0 & Chinese Academy of Sciences, China & $5^{\circ} \times 4^{\circ}$ & $\begin{array}{l}\text { Zhang and } \\
\text { McFarlane (1995) }\end{array}$ \\
\hline giss_aom1 & $\begin{array}{l}\text { National Aeronautics and Space } \\
\text { Administration (NASA) Goddard } \\
\text { Institute for Space Studies (GISS), } \\
\text { United States }\end{array}$ & $4^{\circ} \times 3^{\circ}$ & Russell et al. (1995) \\
\hline
\end{tabular}

$\mathbf{s}_{x}(t)(1 \leq t \leq T)$, it is similar to the pattern of the first CEOF performed over a single time section of length $T$. However, the LMA makes it possible to compute an average pattern from a selection of intraseasonal events. Here, we consider simply the average pattern for all events with a time section centered between June and September. Let them be $\mathbf{Z}^{\text {obs }}(x)$ for observations and $\mathbf{Z}^{\text {mod }}(x)$ for the GCMs (Fig. 1). To have an idea on the number of samples used in this study, GPCP observations has an average of 2.4 organized summer intraseasonal events per year and in the models they range from 2.0 to 2.55 events per year. The average event in the observations
$\left[\mathbf{Z}^{\text {obs }}(x)\right.$, Fig. 1a] is based on 24 events (in 10 years). The clockwise rotation of the segments (representing the phase at a given grid box) indicates the propagation of intraseasonal convection perturbation. In the observations they start at around $5^{\circ} \mathrm{S}, 85^{\circ} \mathrm{E}$ and propagate northward (with also an eastward component) to the north Bay of Bengal and the west coast of India. The models show a wide range of skill in reproducing the observed amplitude and propagation characteristics of the average summer ISV $\left[\mathbf{Z}^{\bmod }(x)\right.$, Fig. 1]. There are a few models [Bjerknes Centre for Climate Research Bergen Climate Model version 2.0 (BCCR-b2.0); Max 
81 events

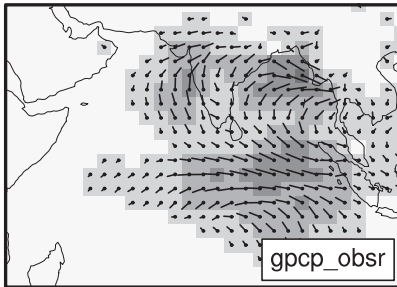

86 events

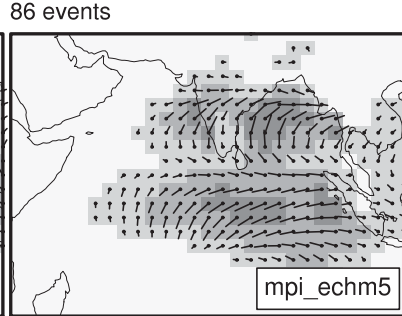

87 events

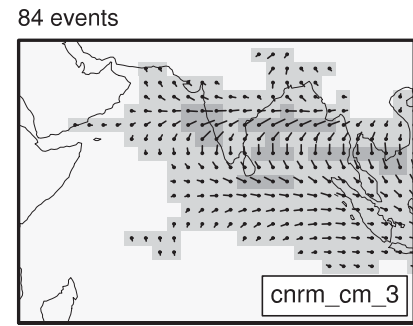

84 events

69 events
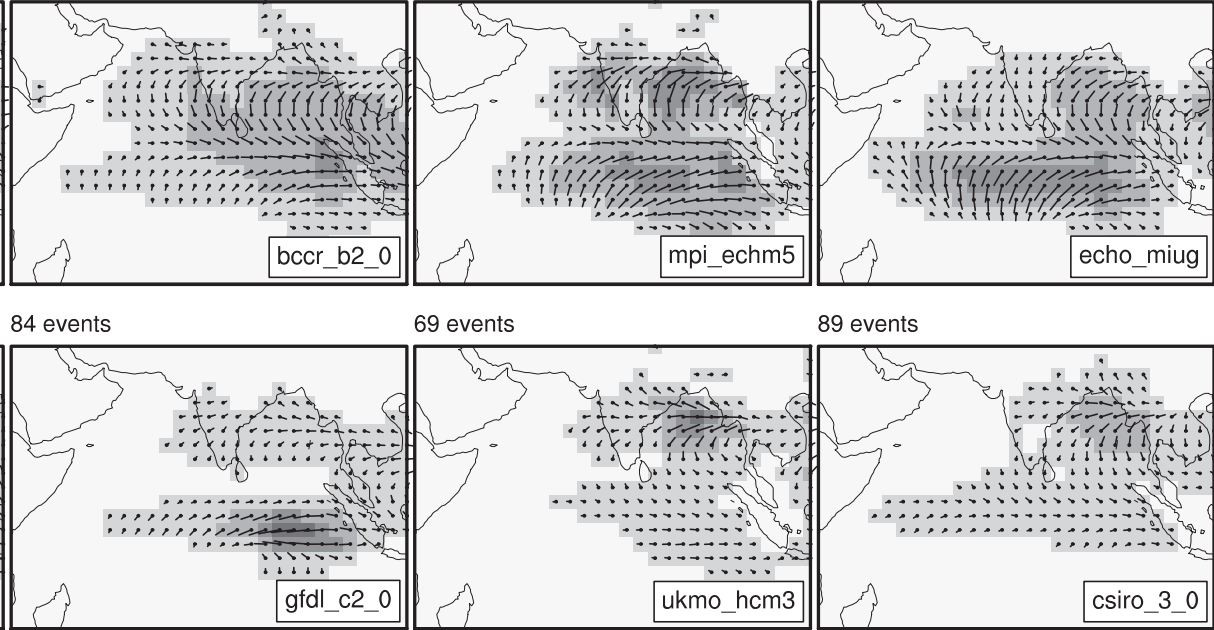

89 events

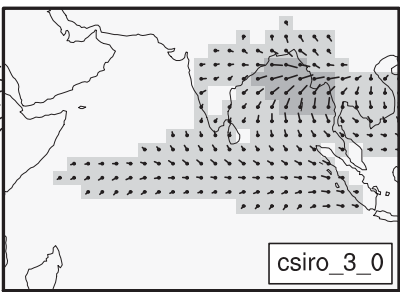

90 events

80 events
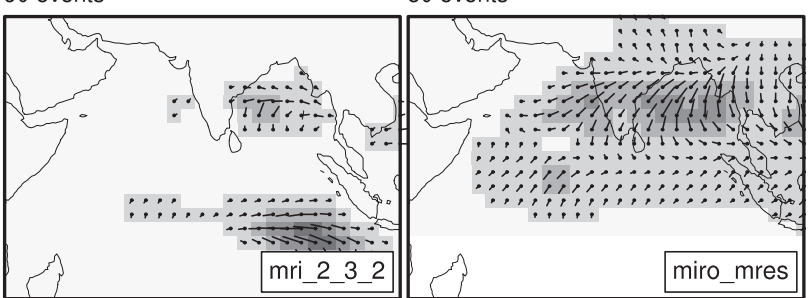

91 events

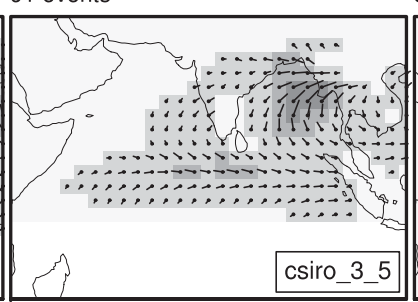

85 events
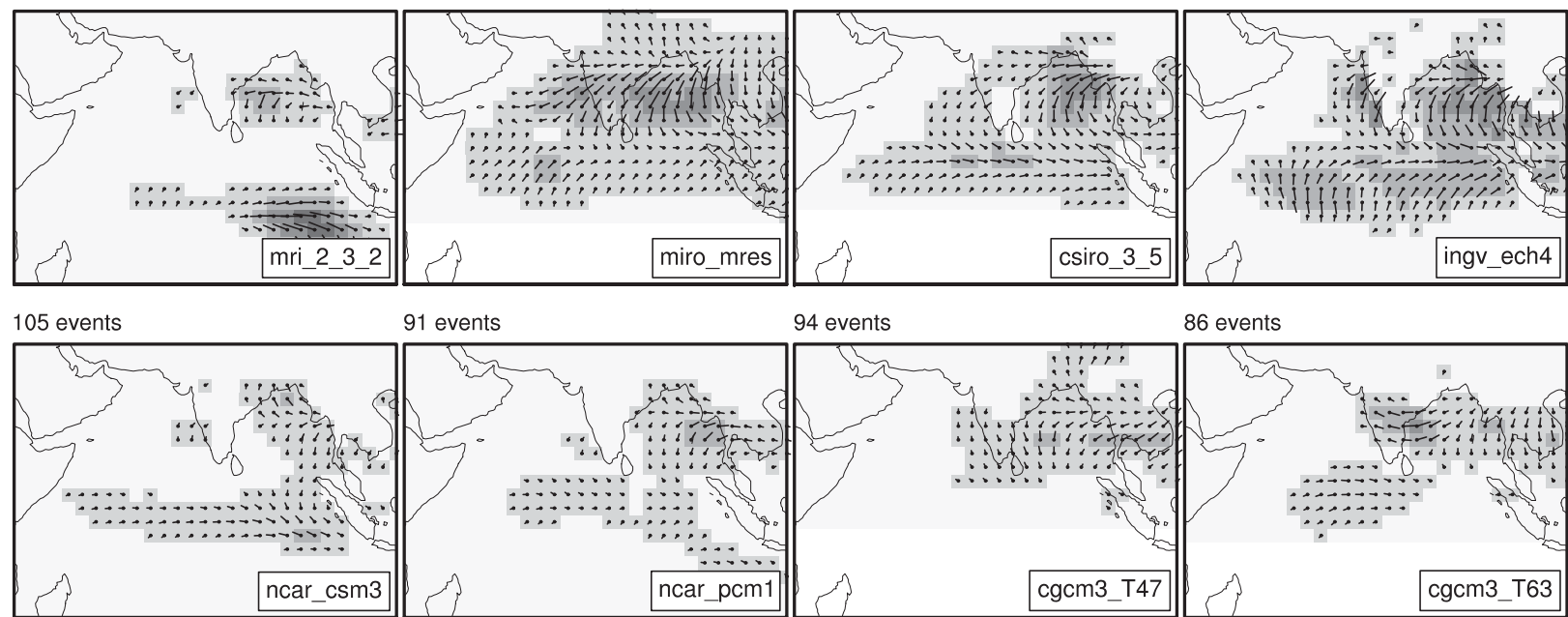

91 events

94 events

86 events
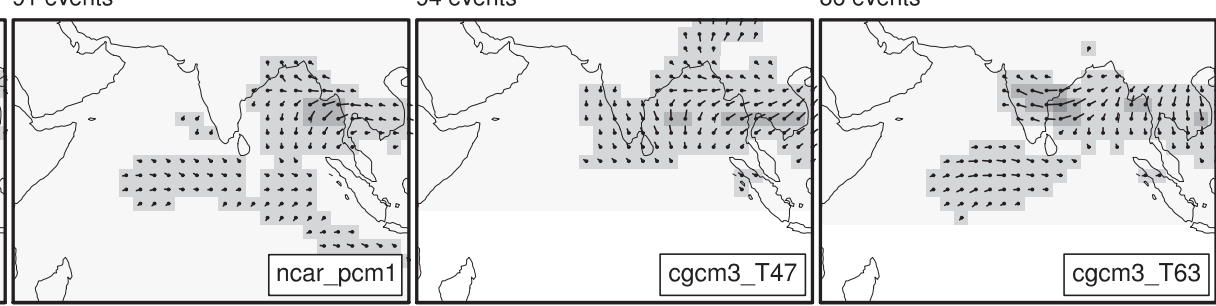

89 events

94 events

84 events
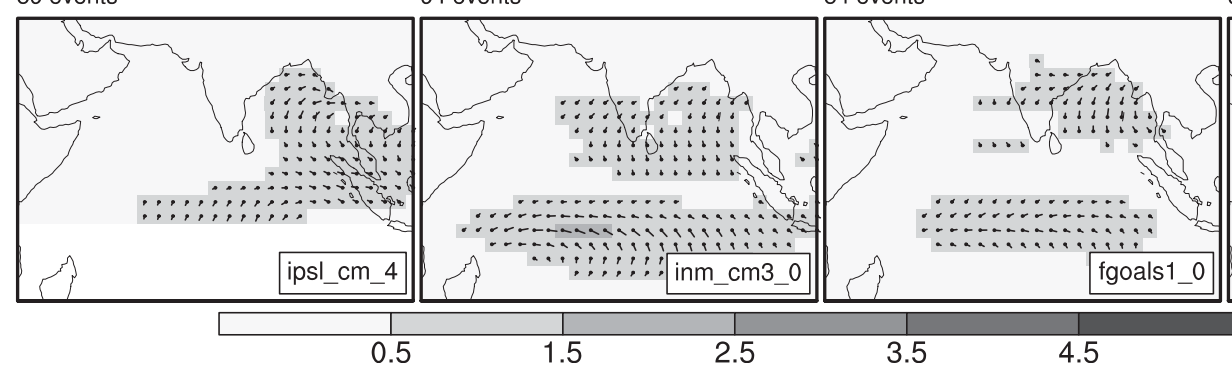

90 events

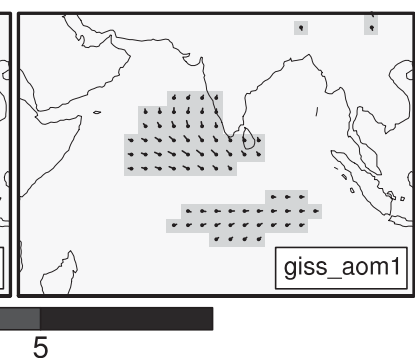

FIG. 1. The average patterns of precipitation ISV for summer [June-September (JJAS)] from the observations and the CMIP3 models. Shades represent the standard deviation of the ISV in $\mathrm{mm} \mathrm{day}^{-1}$. The segment represents the phase of the propagation and its length is proportional to the standard deviation. The angle of segment (phase) increases clockwise with time (e.g., northward propagation for a segment rotating clockwise toward the north). The number of local modes used to construct each pattern is indicated on the top left of each panel. For example, the observed pattern is constructed from 24 events in the 10 years, while in the models it is constructed from a larger number of events. The models are arranged from left to right and top to bottom according to their metric value (see Fig. 3).

Planck Institute (MPI) ECHAM5] that produce a quite realistic average perturbation pattern with their amplitudes and phases resembling the observed pattern. Most models, however, produce either weaker amplitude or shifted position of the perturbation or wrong propagation characteristics. The aim of the present article is to present an objective metric to assess the ability of a GCM to produce not only such an average pattern but also an 


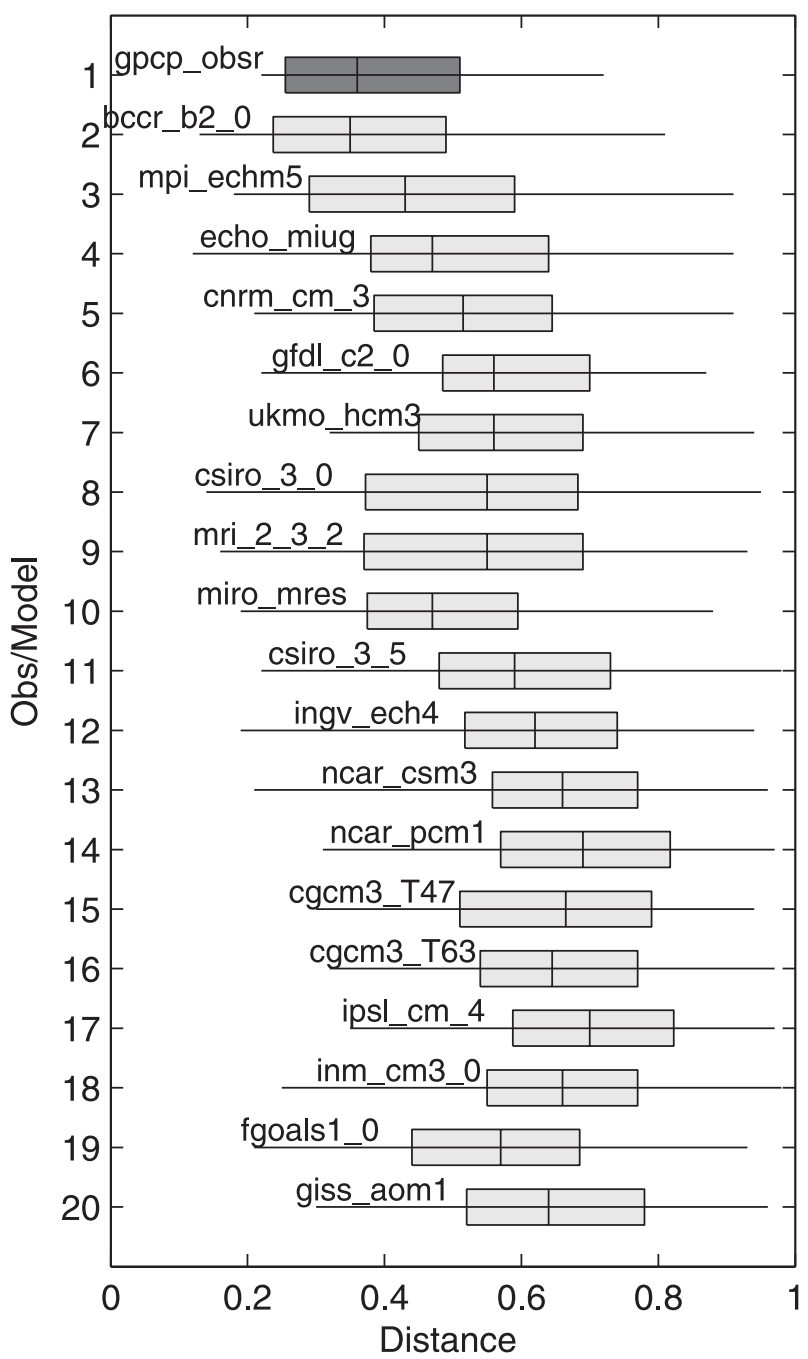

FIG. 2. Distribution of distances between individual intraseasonal events to their average summer ISV pattern in the observations and models. The bars range from the 25 th percentile to the 75 th percentile. The horizontal line represents the range of values and the median (50th percentile) are represented by the vertical lines on each bar. The models are arranged from top to bottom according to their metric value (see Fig. 3).

ensemble of spatially organized, reproducible, and realistic intraseasonal events.

\section{Reproducibility, realism, and model evaluation metric}

Unlike in the conventional average diagnostics of ISV, LMA provides more insight into the construction of the average intraseasonal perturbation pattern and its resemblance to the observed. In this study we focus on two important aspects that define the quality of ISV represented in GCMs, namely (i) the event-to-event reproducibility of each ISV event and (ii) their degree of realism. Since individual intraseasonal events are not necessarily identical, the average spatial perturbation pattern $\mathbf{Z}(x)$ must be complemented with a measure of its resemblance with the patterns of each event $\mathbf{Z}_{m}(x)$ used to compute it. Such a measure will be useful to verify if the average pattern is representative of the different intraseasonal events, that is, if it is appropriate to give a physical interpretation of the average pattern or if it is merely a mathematical object resulting from a combination of varied events. This resemblance is computed as the normalized distance $\delta(m)$ between the complex eigenvectors representing the average pattern $\mathbf{Z}(x)$ and the pattern of each individual event $\mathbf{Z}_{m}(x)$. Here $\delta(m)$ is calculated considering the phase that minimizes the distance between the vectors (see GD2000). Such a minimization is necessary since two eigenvectors that are identical, except for a constant phase difference, represent actually the same mode. The distance increases as the amplitude and the phase differences between the vector components increase. Therefore, they compare the spatial distribution of amplitude and phases of each ISV event to the average pattern. The convention is that the patterns are identical for a normalized distance of 0 and orthogonal for a distance of 1 . The measure of reproducibility [say, $\delta_{\text {rep }}(m)$ ] in the observations is computed as the distance between $\mathbf{Z}^{\text {obs }}(x)$ and $\mathbf{Z}_{m}^{\text {obs }}(x)$ and between $\mathbf{Z}^{\bmod }(x)$ and $\mathbf{Z}_{m}^{\bmod }(x)$ in the GCMs. The frequency distribution of the distances $\delta_{\text {rep }}(m)$ is given in Fig. 2.

The observed intraseasonal events have all distances less than 0.7 with an median value of 0.36 signifying the robustness of individual intraseasonal events $\mathbf{Z}_{m}^{\text {obs }}(x)$ in the construction of the average spatial perturbation pattern $\left[\mathbf{Z}^{\text {obs }}(x)\right]$. This justifies the use of an average diagnostic such as EOF analysis, composite, or regression to describe the Indian Ocean ISV in the observations. However, in most models, these distances are quite large (average distance around 0.6 for many models), indicative of rather irregular and less-reproducible events. This is a caution on the use of assessment approaches that assume that the modeled ISV is as regular and reproducible as the observed ISV. Such approaches may yield average ISV patterns that are more of mathematical objects constructed by several less-reproducible events in the models and hence a proper physical interpretation of the average perturbation patterns may be difficult. However, there are some models having reproducibility comparable to the observations (e.g., BCCR-b2.0; MPI ECHAM5). The robustness of average patterns presented in Fig. 1 depends strongly on these distributions. The average pattern for models with large spread and large average distances must be interpreted with caution since very few actual intraseasonal perturbation patterns $\mathbf{Z}_{m}^{\text {mod }}(x)$ are similar to the average pattern $\mathbf{Z}^{\bmod }(x)$. It should, however, be noted that the statistics in this 


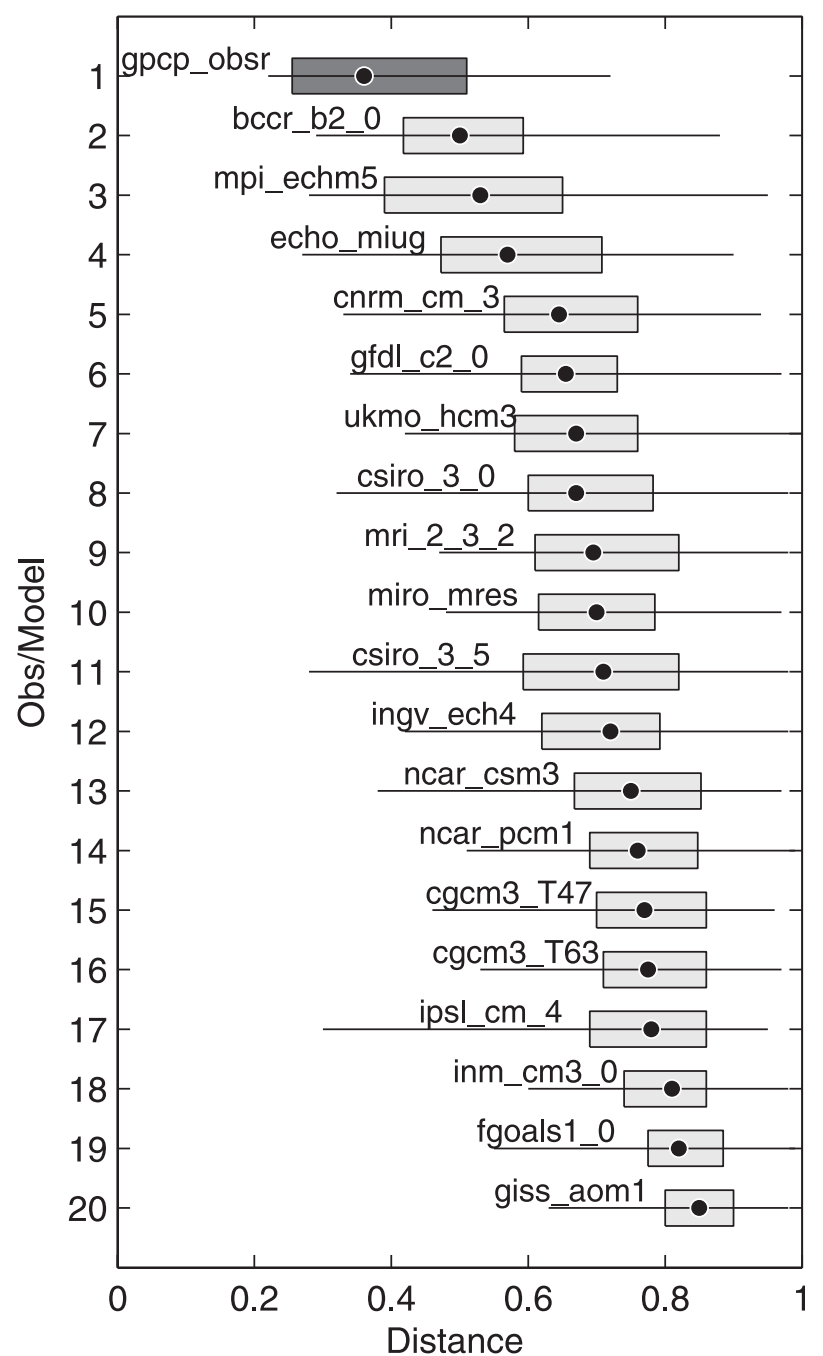

FIG. 3. Distribution of distances between individual intraseasonal events to the observed average summer ISV pattern in the observations and models. The bars range from the 25 th percentile to the 75 th percentile. The line represents the range of values. The median (50th percentile) is denoted by the black dots. Models are arranged according to the median distance.

study applies only for the Indian Ocean basin for summer and may vary depending on the size of the basin and the season considered. For instance, Duvel and Vialard (2007) show that these distances are quite small in the observations while considering only the Indian Ocean basin in summer, but larger when considering also the northwest Pacific.

A desirable property of an ISV evaluation metric in GCMs is that it incorporates several elements of model representation of the phenomenon. The approach described above may be extended to evaluate the realism of simulated ISV patterns. This realism is given by the distribution of the distances $\delta_{\text {real }}(m)$ between simulated patterns $\mathbf{Z}_{m}^{\text {mod }}(x)$ and the average observed pattern $\mathbf{Z}^{\text {obs }}(x)$ (given in Fig. 1, top left). In the observations, $\delta_{\text {real }}(m)$ equals $\delta_{\text {rep }}(m)$ by definition. The frequency distributions of these distances of the 19 IPCC models are given in Fig. 3. As expected, these distances are significantly larger for most models compared to those in Fig. 2, suggesting that, even though some models produce reasonably reproducible intraseasonal events, they are quite far from reality. The average multimodel distance distribution peaks at 0.75. A few models (BCCR-b2.0 and MPI ECHAM5, for instance) produce reasonably reproducible and realistic intraseasonal events.

An objective evaluation metric for the ISV in climate models is derived based on the above diagnostics. The metric can be summarized by considering only the 50th percentile value (median) of $\delta_{\text {real }}(m)$ (a software package to compute the metric is available online at http:// www.lmd.ens.fr/jpduvel/lma/LMA_Metric.html). Therefore, a lower value of the so-defined metric indicates that more intraseasonal events have realistic patterns. The metric value is shown as black dots in Fig. 3. The models are arranged in the order of their metric value for the Indian Ocean region in boreal summer. The values of the metric presented here apply to the Indian Ocean region during boreal summer and they may vary depending on either the region or season considered. The simulated average intraseasonal perturbation patterns (Fig. 1) reveal that the models that have reasonable ISV amplitudes (shades in Fig. 1), propagation characteristics (shown as the phases), and locations of convection centers have smaller values of the metric. Models with larger values of the metric generally produce much weaker ISV amplitude.

The ability of a model to simulate the large-scale organization of the ISV of the convection may also be diagnosed using LMA results. This diagnostic is based on the regional LMA variance $\mathbf{A}_{m}(x)^{2}$ of each event. This LMA variance is the part of the signal having common spectral characteristics with other regions [the spectral key $\psi_{m}(k)$ ] during the intraseasonal event. The ratio between the LMA variance and the variance of the 20-90-day signal over the same time segment is thus an indicator of the part of the local signal corresponding to the large-scale intraseasonal perturbation. The average ratio over all intraseasonal events (Fig. 4) thus highlights regions strongly impacted by large-scale organized events. The observed ratio is large (with values larger than 0.7 ) over the eastern equatorial Indian Ocean, which is a source region of the convective intraseasonal perturbations in summer. The high values over the Bay of Bengal and eastern Arabian Sea suggest that most of the ISV of the convection over this region is due to large-scale organized convective perturbations. The ratio for each model is arranged according the metric in Fig. 3. For models with a good ISV metric, 

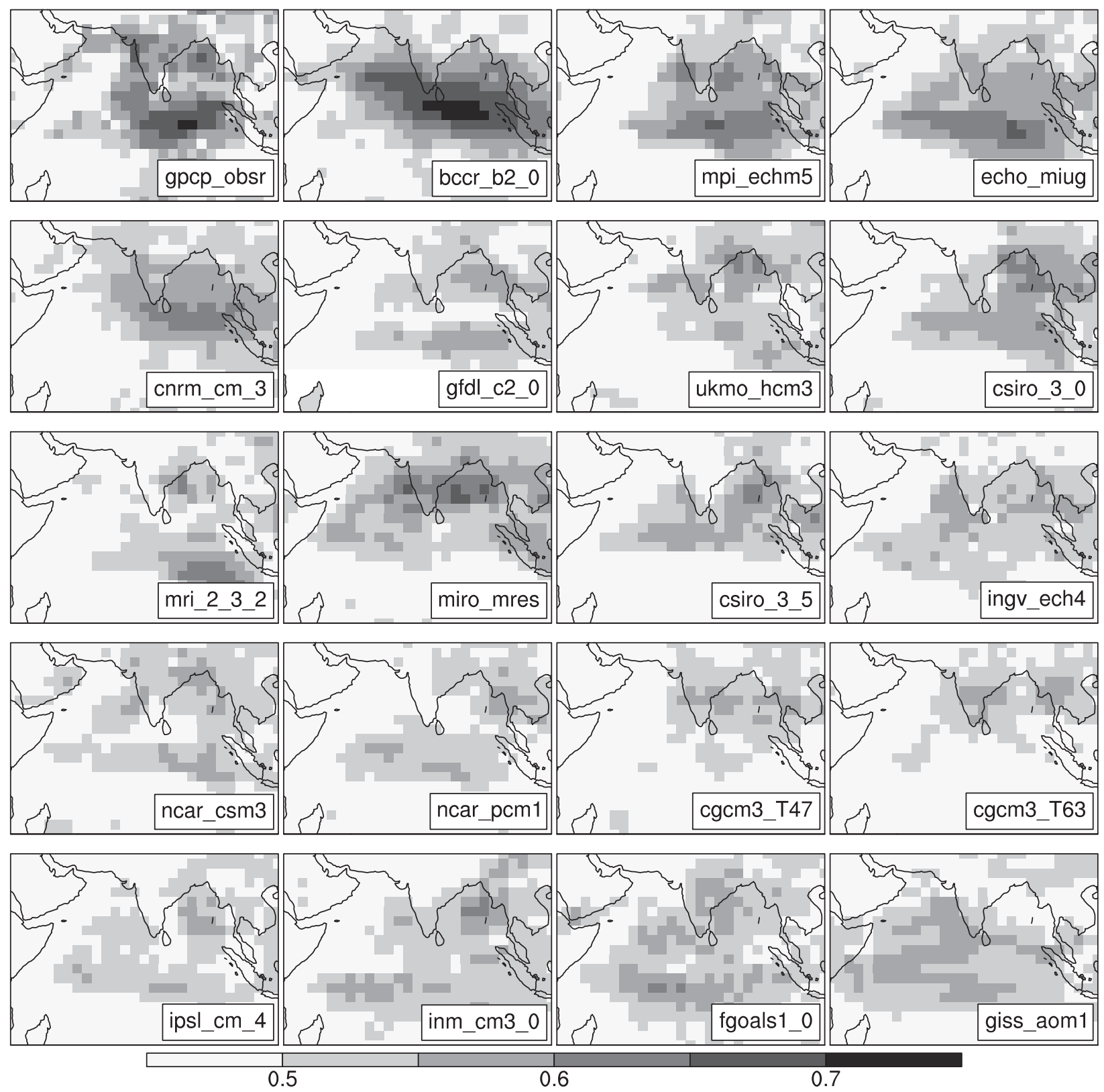

FIG. 4. Ratio of amplitude of each individual large-scale organized ISV event over a 90-day time segment to the amplitude of the 20-90-day bandpass filtered rainfall amplitude over the same time segment. The value for a particular region represents the average contribution of large-scale organized convective perturbations to the local, more stochastic (or related to local instability) rainfall variability.

the ratio is comparable to the observations in both magnitude and location with, in particular, a maximum ratio for the east equatorial Indian Ocean. Models with a poor ISV metric tend to produce a smaller ratio and, generally, wrong position of the maximum values. A smaller ratio reveals that large-scale organized events have a weaker impact on the regional ISV. A possible consequence is that the convective heating perturbation is organized at a smaller scale, giving a too weak dynamical response (Bellenger et al. 2009). The link between the ratio and the
ISV metric thus suggests that part of the problem in simulating the ISV can be related to the lack of large-scale organization of the convection, either for the triggering of the intraseasonal events or for its evolution.

\section{Scale interactions}

Kitoh (2006) presents a review on the future changes of the South Asian summer monsoon due to $\mathrm{CO}_{2}$ increase as projected by the state-of-the-art climate models. 
Although a few studies reported that the South Asian summer monsoon becomes weak or there is no significant change in precipitation (Zhao and Kellogg 1988; Lal and Singh 2001), most models show that the seasonal mean precipitation increases and interannual variability increases as well (Meehl and Washington 1993; Bhaskaran et al. 1995; Kitoh et al. 1997; Douville et al. 2000; Meehl and Arblaster 2003). The projections of these regional-scale climate changes, however, are highly model dependent and there are large differences among models for projected changes in monsoon precipitation, including even the sign of change (Kitoh 2006 and references therein). The seamless prediction paradigm (Palmer et al. 2008) postulates that the large uncertainties in the projected climate change are at least due in part to the fact that the models do not accurately capture the weatherclimate link. ISV is known as an important component of the monsoon system that interacts with the synoptic weather events and the seasonal mean and interannual variations (Goswami et al. 2006). How accurate the statistics of the collection of synoptic weather systems at the high frequency $(\mathrm{HF})$ end of the spectrum is represented in a model can possibly influence the ISV and seasonal to interannual time scales and beyond. The ISV evaluation metric defined in this study can be a useful tool in assessing the link between the high-frequency variability and the climatology of CMIP3 models. In this section we examine the relationship between the HF variability, the ISV representation, and the monsoon precipitation climatology in each model and observations.

The Fourier power spectra of the detrended time series of precipitation for each grid point in the domain $25^{\circ} \mathrm{N}-0^{\circ}, 70^{\circ}-100^{\circ} \mathrm{E}$ for each summer is calculated and the average spectra are shown in Fig. 5a. Most models seriously underestimate HF power, and only a couple of models produce realistic variance in the 10-60-day band. Intriguingly, contrary to the observations, most models produce strongly reddened power spectra (with large power at low frequencies), as noted by Lin et al. (2008) as well. The redness of the spectrum of each model is estimated by the ratio between variances in the intraseasonal and the HF band. A comparison of the ratio and the model evaluation metric (Fig. 5b) shows a significant ( $r=0.47$ at $95 \%$ level) relationship. Models that tend to produce realistic intraseasonal perturbation patterns have more realistic variance (Fig. 5c) and have reduced and more realistic spectral redness.

The simulated seasonal average rainfall distribution can be evaluated by computing the spatial correlation between simulated and observed rainfall maps. Since the ISV modulates the position of the ITCZ in the course of the monsoon season, there may be a link between the characteristics of the intraseasonal events and the average rainfall distribution. One could therefore try to verify if models with a good ISV metric also produce a good average rainfall distribution. A correlation of -0.62 (significant at 99\% level) suggests a strong tendency for models with better ISV realism metric to have more spatially consistent monsoon rainfall climatology (Fig. 6). It is, however, not trivial to establish a direction of causality for such a link since a correct location of the convective variability at all time scales (synoptic to intraseasonal) is obviously dependent on the correct location of the ITCZ. The ISV realism metric implicitly takes this fact into account since a small distance between observed and simulated ISV patterns implies a correct simulation of the main rainfall areas. In such a case, the ISV realism metric will be mathematically related to this correlation and hide a possible effect of the ISV on the representation of the average rainfall distribution. However, the ISV reproducibility (Fig. 2) is independent of the observed average rainfall distribution and can be compared. A link between these two factors will indicate that the ability of a model to give reproducible intraseasonal events is somewhat linked to its ability to give a correct average rainfall distribution. There is, indeed, a correlation of -0.44 between these two factors that is significant at the $95 \%$ level. This may also indicate that well-organized and reproducible intraseasonal events can develop only in realistic mean states. The precise knowledge of the origin of this link needs analyses that are outside the scope of this study.

\section{Summary and discussions}

Diagnostics on the representation of summer ISV over the Indian Ocean in the CMIP3 models are presented with a focus on event-to-event reproducibility and realism. The LMA used here provides a measure of the reproducibility and realism by identifying in a single mathematical form: the perturbation pattern of each individual organized convective ISV event. This measure evaluates the robustness of the average ISV perturbation pattern (Fig. 1). Second, the resemblance of simulated intraseasonal events to a typical observed pattern is measured for each simulated ISV event, and the most probable distance is presented as a metric for evaluating the simulation of tropical ISV. This gives an objective evaluation of simulated ISV in terms of their amplitude, propagation characteristics, and reproducibility from one event to the other.

The models show a wide range of skills in representing the ISV. There are a few models that produce realistic amplitude, propagation characteristics, and event-toevent reproducibility. Xavier et al. (2008) pointed out a few issues in representing the intraseasonal air-sea 
(a) Power spectra over Bay of Bengal

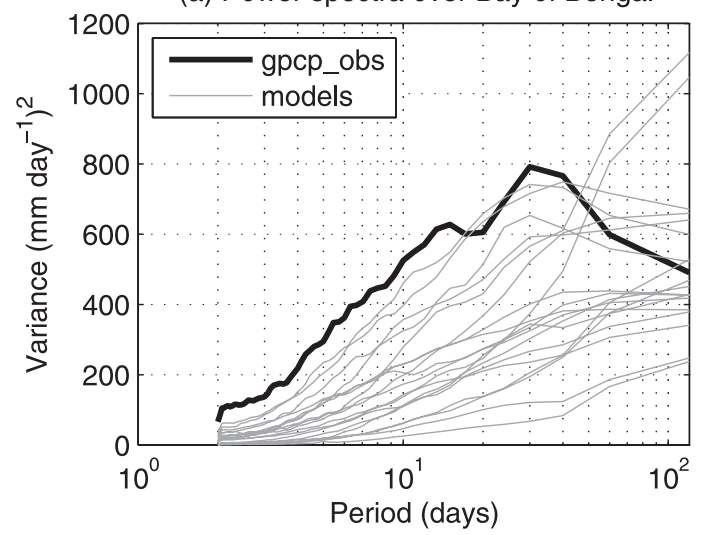

(c) 2-60 days variance vs ISV metric

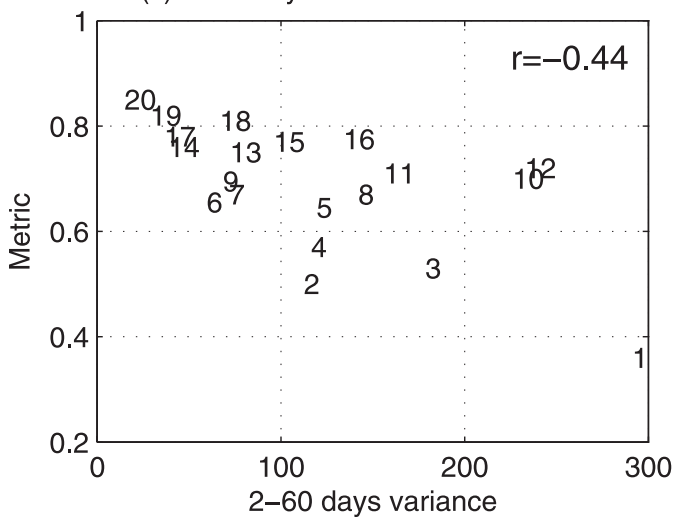

(b) Redness vs ISV metric

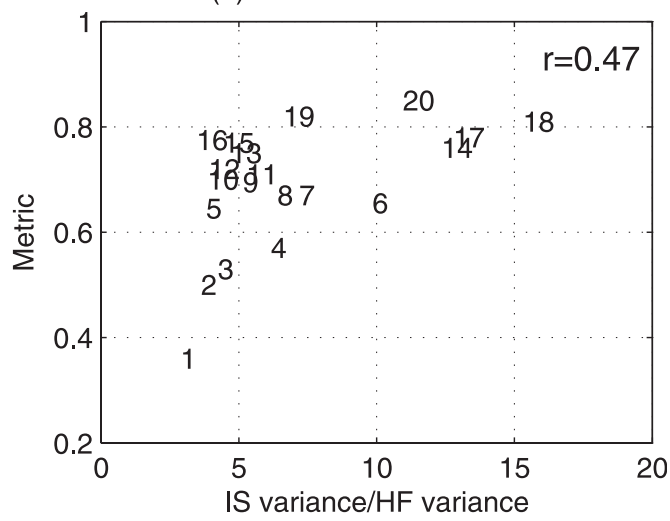

FIG. 5. (a) Detrended power spectra of JJAS rainfall averaged over $25^{\circ} \mathrm{N}-0^{\circ}, 70^{\circ}-100^{\circ} \mathrm{E}$ in the observations and the models. (b) The relationship of the ISV metric to the redness of the spectra defined as the ratio of 10-60-day variance to the 2-10-day variance. (c) The relationship between the metric and total variance in the 2-60-day band. Each model is marked with a number as in Fig. 3 according to the metric. The linear correlation values (excluding the observations) in (b) and (c) are indicated.

interaction processes. The lack of representation of diurnal SST variability and the associated coupled feedbacks were proposed to be a source of the DEMETER model biases. This, however, would require experiments with models that can resolve the oceanic mixed layer and exchange of fluxes with the atmosphere at subdiurnal intervals. The convective parameterization is known to have a strong impact in the climate models whose signatures can be found even in the deep ocean circulation (Braconnot et al. 2007). For Atmospheric Model Intercomparison Project I (AMIP I) simulations, Slingo et al. (1996) noted that the models with reasonable levels of intraseasonal activity used convection schemes with a closure on buoyancy rather than on moisture supply. Several recent analyses demonstrated improved MJO simulations for models with mass-flux convection schemes that use adjustment type of closures (Liu et al. 2005). However, these findings may be arguable since Wang and Schlesinger (1999) demonstrated that it is possible to alter substantially the strength of the
MJO by modifying the particular trigger used within the convection scheme as well as the fundamental scheme itself. The large sensitivity of ISV simulation demands more dedicated analysis before any conclusions are drawn on the advantages or drawbacks of any particular convection scheme. Considering that the large-scale convective organization depends largely on the convective parameterization, our metric is able to classify the models based on the convective organization and thereby highlights the need for improvements in convection schemes. This enhances the utility of the metric as a diagnostic tool since it can evaluate the drawbacks in parameterized physics and the complex feedbacks. One observation is that, as shown in the Table 1, the BCCR and Centre National de Recherches Météorologiques (CNRM) models have the same atmospheric model [Action de Recherche Petite Echelle Grande Echelle Climate Model (ARPEGE-Climat) Version 3], and there is a marked improvement in the ISV amplitude in BCCR compared to CNRM, even though the 


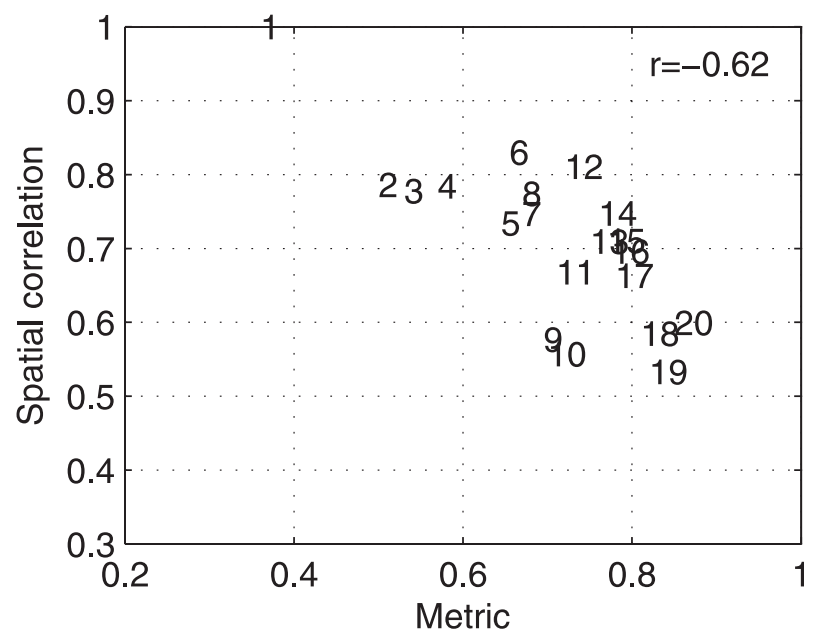

FIG. 6. The relationship between the ISV metric and the spatial correlation between simulated and observed climatological rainfall over $20^{\circ} \mathrm{S}-25^{\circ} \mathrm{N}, 60^{\circ}-110^{\circ} \mathrm{E}$. Each model is marked with a number as in Fig. 3 according to the metric. The linear correlation (excluding the observations) value is -0.62 .

spatial structure of ISV remains nearly the same. This improvement could be attributed to a modification in which the sea surface current is accounted for when the turbulent surface fluxes are computed. The extent to which surface fluxes are affected by this modification is not known, but it certainly signifies the importance for accurate modeling of atmosphere-ocean fluxes to represent realistic ISV properties.

The ISV evaluation metric bears a significant relationship with the representation of both HF variance and seasonal mean climate. In a seamless modeling context, it is postulated that synoptic-scale weather systems could possibly impact the ISV through the modification of ocean heat content and the associated air-sea interaction processes. An important link that bridges the gap between weather and climate over the Asian monsoon region is the ISV, and its realistic representation is certainly important to produce a reasonable mean state. The issue is thus to know what are the important missing elements for a correct representation of the internal variability and what is the best strategy for incorporating them into the coupled models. Interestingly, most models producing reddened rainfall spectra also produce too weak $\mathrm{HF}$ variance. As suggested by Lin et al. (2008), the weak dayto-day variance could result from the absence of selfsuppression mechanisms of convection in the models. For example, the dry (or unsaturated) downdrafts associated with convection can cool the surface and reduce the temperature and humidity gradients in the lower troposphere, thereby reducing the buoyancy and moisture availability at the surface. Such a mechanism has the potential to suppress the convective activity for the days following organized active convective spells. This gives thus a larger HF variance of the precipitation at both synoptic and intraseasonal time scales. By contrast, models with poor $\mathrm{HF}$ variability will exhibit mostly a slow evolution of the precipitation field, following more the seasonal forcing and resulting in an overreddened spectrum. This "reddish" character will be reduced for models with better HF variance, which explains why these models also have a more realistic spectrum. According to our metrics, these are also models with the better ISV in the tropics, showing the potential importance of the mechanisms described above.

Acknowledgments. The IPCC AR4 data is obtained from the WCRP CMIP3 multimodel database. We thank the Program for Climate Model Diagnosis and Intercomparison (PCMDI) for collecting and archiving the CMIP3 model output and the WCRP Working Group on Coupled Modeling (WGCM) for organizing the model data analysis activity. GPCP 1DD data are obtained from http://www1.ncdc.noaa.gov/pub/data/gpcp/. The authors thank Hervé Douville for his comments on a previous version of the article. PKX and FJDR are supported by the European ENSEMBLES project.

\section{REFERENCES}

Bellenger, H., and J. P. Duvel, 2007: Intraseasonal convective perturbations related to the seasonal march of the Indo-Pacific monsoons. J. Climate, 20, 2853-2863.

, M. Lengaigne, and P. Levan, 2009: Impact of organized intraseasonal convective perturbations on the tropical circulation. Geophys. Res. Lett., 36, L16703, doi:10.1029/2009GL039584.

Betts, A. K., 1986: A new convective adjustment scheme. Part I. Observational and theoretical basis. Quart. J. Roy. Meteor. Soc., 112, 677-691.

Bhaskaran, B., J. Mitchell, J. Lavery, and M. Lal, 1995: Climatic response of the Indian subcontinent to doubled $\mathrm{CO}_{2}$ concentrations. Int. J. Climatol., 15, 873-892.

Bougeault, P., 1985: A simple parameterization of the large-scale effects of cumulus convection. Mon. Wea. Rev., 113, 2108-2121.

Braconnot, P., F. Hourdin, S. Bony, J. L. Dufresne, J. Y. Grandpeix, and O. Marti, 2007: Impact of different convective cloud schemes on the simulation of the tropical seasonal cycle in a coupled ocean-atmosphere model. Climate Dyn., 29, 501-520.

Douville, H., J.-F. Royer, J. Polcher, P. Cox, N. Gedney, D. Stephenson, and P. Valdes, 2000: Impact of $\mathrm{CO}_{2}$ doubling on the Asian summer monsoon: Robust versus modeldependent responses. J. Meteor. Soc. Japan, 78, 421-439.

Duvel, J. P., and J. Vialard, 2007: Indo-Pacific sea surface temperature perturbations associated with intraseasonal oscillation of the tropical convection. J. Climate, 20, 3056-3082.

Emanuel, K. A., 1991: A scheme for representing cumulus convection in large-scale models. J. Atmos. Sci., 48, 2313-2335.

Goswami, B. N., 2005: The Asian monsoon: Interdecadal variability. The Global Monsoon System: Research and Forecast, C.-P. Chang, B. Wang, and N.-C. G. Lau, Eds., World Meteorological Organization, WMO/TD 1266, 455-471. 
R. S. Ajayamohan, P. K. Xavier, and D. Sengupta, 2003: Clustering of synoptic activity by Indian summer monsoon intraseasonal oscillations. Geophys. Res. Lett., 30, 1431, doi:10.1029/2002GL016734.

—, G. Wu, and T. Yasunari, 2006: Annual cycle, intraseasonal oscillations and roadblock to seasonal predictability of the Asian summer monsoon. J. Climate, 19, 5078-5099.

Goulet, L., and J. P. Duvel, 2000: A new approach to detect and characterize intermittent atmospheric oscillations: Application to the intraseasonal oscillation. J. Atmos. Sci., 57, 23972416.

Gregory, D., and P. R. Rowntree, 1990: A mass flux convection scheme with representation of cloud ensemble characteristics and stability-dependent closure. Mon. Wea. Rev., 118, 1483-1506.

Huffman, G. J., R. Adler, M. Morrissey, D. Bolvin, S. Curtis, R. Joyce, B. McGavock, and J. Susskind, 2001: Global precipitation at one-degree daily resolution from multisatellite observations. J. Hydrometeor., 2, 36-50.

Kitoh, A., 2006: Asian monsoons in future. The Asian Monsoon, B. Wang, Ed., Springer/Praxis Publishing, 631-649.

— , S. Yukimoto, A. Noda, and T. Motoi, 1997: Simulated changes in the Asian summer monsoon at times of increased atmospheric $\mathrm{CO}_{2}$. J. Meteor. Soc. Japan, 75, 1019-1031.

Lal, M., and S. K. Singh, 2001: Global warming and monsoon climate. Mausam (New Delhi), 52, 245-262.

Lin, J. L., and Coauthors, 2006: Tropical intraseasonal variability in 14 IPCC AR4 climate models. Part I: Convective signals. J. Climate, 19, 2665-2690.

-, K. Weickman, G. Kiladis, B. Mapes, S. Schubert, M. Suarez, J. Bacmeister, and M. Lee, 2008: Subseasonal variability associated with Asian summer monsoon simulated by 14 IPCC AR4 Coupled GCMs. J. Climate, 21, 4541-4567.

Liu, P., B. Wang, K. Sperber, T. Li, and G. Meehl, 2005: MJO in the NCAR CAM2 with the Tiedtke convective scheme. J. Climate, 18, 3007-3020.

Madden, R. A., and P. R. Julian, 1994: Observations of the 40-50-day tropical oscillation: A review. Mon. Wea. Rev., 122, 813-837.

Meehl, G. A., and W. M. Washington, 1993: South Asian summer monsoon variability in a model with doubled atmospheric carbon dioxide concentration. Science, 260, 1101-1104.

— changes in South Asian monsoon precipitation. Climate Dyn., 21, 659-675.

Moorthi, S., and M. J. Suarez, 1992: Relaxed Arakawa-Schubert: A parameterization of moist convection for general circulation models. Mon. Wea. Rev., 120, 978-1002.
Nordeng, T. E., 1994: Extended versions of the convective parameterization scheme at ECMWF and their impact on the mean and transient activity of the model in the tropics. European Centre for Medium-Range Weather Forecasts, ECMWF Tech. Memo. 206, 41 pp.

Palmer, T. N., F. Doblas-Reyes, A. Weisheimer, and M. Rodwell, 2008: Toward seamless prediction: Calibration of climate change projections using seasonal forecasts. Bull. Amer. Meteor. Soc., 89, 459-470.

Pan, D.-M., and D. A. Randall, 1998: A cumulus parameterization with a prognostic closure. Quart. J. Roy. Meteor. Soc., 124, 949-981.

Russell, G. L., J. R. Miller, and D. Rind, 1995: A coupled atmosphereocean model for transient climate change studies. Atmos.-Ocean, 33, 683-730.

Slingo, J. M., and Coauthors, 1996: Intraseasonal oscillations in 15 atmospheric general circulation models: Results from an AMIP diagnostic subproject. Climate Dyn., 12, 325-357.

Sperber, K. R., and Coauthors, 2001: Dynamical seasonal predictability of the Asian summer monsoon. Mon. Wea. Rev., 129, 2226-2248.

Tiedtke, M., 1989: A comprehensive mass flux scheme for cumulus parameterization in large-scale models. Mon. Wea. Rev., 117, 1779-1800.

Waliser, D. E., and Coauthors, 2003: AGCM simulations of intraseasonal variability associated with the Asian summer monsoon. Climate Dyn., 21, 423-446.

Wang, W., and M. E. Schlesinger, 1999: The dependence on convection parameterization of the tropical intraseasonal oscillation simulated by the UIUC 11-layer atmospheric GCM. J. Climate, 12, 1423-1457.

Wheeler, M., and K. Weickmann, 2001: Real-time monitoring and prediction of modes of coherent synoptic to intraseasonal tropical variability. Mon. Wea. Rev., 129, 2677-2694.

_ , and H. H. Hendon, 2004: An all-season real-time multivariate MJO index: Development of an index for monitoring and prediction. Mon. Wea. Rev., 132, 1917-1932.

Xavier, P. K., J.-P. Duvel, and F. J. Doblas-Reyes, 2008: Boreal summer intraseasonal variability in coupled seasonal hindcasts. J. Climate, 21, 4477-4497.

Zhang, G. J., and N. A. McFarlane, 1995: Sensitivity of climate simulations to the parameterization of cumulus convection in the Canadian Climate Centre General Circulation Model. Atmos.-Ocean, 33, 407-446.

Zhao, Z., and W. Kellogg, 1988: Sensitivity of soil moisture to doubling of carbon dioxide in climate model experiments. Part II: The Asian monsoon region. J. Climate, 1, 367-378. 